\title{
Power Converter Control Circuits for Two-Mass Vibratory Conveying System With Electromagnetic Drive: Simulations and Experimental Results
}

\author{
Željko V. Despotović, Member, IEEE, and Zoran Stojiljković
}

\begin{abstract}
A mathematical model of two-mass vibratory conveying system with electromagnetic vibratory actuator (EVA) and possible ways of their optimal control by using power converter is presented in this paper. Vibratory conveyors are commonly used in industry to carry a wide variety of particulate and granular materials. Application of electromagnetic vibratory drive combined with power converters provides flexibility during work. The use of a silicon-controlled rectifier (SCR) implies a phase angle control, which is very easy, but with many disadvantages (fixed frequency which is imposed by ac mains supply, poor power factor, mechanical retuning, etc.). Switching converters overcomes these disadvantages. Only then, driving for EVA does not depend on mains frequency. As well as amplitude and duration of excitation force tuning, it is also possible to tune its frequency. Consequently, complicated mechanical tuning is eliminated and seeking resonant frequency is provided. Previously mentioned facts motivated phase angle control and switch mode control behavior research for electromagnetic vibratory drives. Simulation and experimental results and their comparisons are exposed in this paper. The simulation model and results are given in the program package PSPICE. Experimental results are recorded on implemented control systems for SCR and transistor power converters. Partial results concerning the resonant frequency seeking process with transistor converter are also exposed.
\end{abstract}

Index Terms-AC-DC power conversion, actuators, conveyors, current control, phase control, resonance, silicon-controlled rectifier (SCR), switching circuits.

\section{INTRODUCTION}

$\mathbf{V}$ IBRATORY movements represent the most efficient way of granular and particulate materials conveying. The conveying process is based on a sequential throw movement of particles. Vibrations of tank, i.e., "load-carrying element" (LCE), in which the material is placed, induce the movement of material particles, so that they resemble a highly viscous liquid, and the material becomes easier to transport and to dose. Due to influences of many factors, the process of conveyance by vibration of granular loads is very complicated. The studies of physical process characteristics and establishment of conveyance speed

Manuscript received November 3, 2004; revised April 20, 2006. Abstract published on the Internet November 30, 2006. This work was supported by the Serbian Ministry of Science and Environmental Protection.

Ž. V. Despotović is with the Mechatronics Laboratory, Mihajlo Pupin Institute, 11000 Belgrade, Serbia and Montenegro (e-mail: zeljko@ robot.imp. bg.ac.yu; zdespot@hotmail.com).

Z. Stojiljković is with the Department of Electrical Engineering, Laboratory of Power Converters, University of Belgrade, 11000 Belgrade, Serbia and Montenegro (e-mail: zorans@galeb.etf.bg.ac.yu).

Digital Object Identifier 10.1109/TIE.2006.888798 dependence from parameters of the oscillating regime are exposed in [1]-[4]. These parameters are frequency and amplitude oscillations of LCE and waveform of the LCE kinematics trajectory. There are also references that consider dependence of particles velocity from angle of vibration and inclination of the LCE [5], [6].

The conveying material flow directly depends on the average value of particles throw movements, being on a certain LCE working vibration frequency. This average value, on the other hand, depends on vibratory width, i.e., doubled amplitude oscillation, of the LCE. Optimal transport is determinated by drive type. It is within the frequency range $5 \mathrm{~Hz}-120 \mathrm{~Hz}$ and the vibratory width range $0.1 \mathrm{~mm}-20 \mathrm{~mm}$, for most materials [1], [7].

Different drive types can achieve mechanical vibrations of the conveying element. The very first drives were originally mechanical (pneumatics, hydraulics, and inertial). Today, most of the common drives are electrical. When a reciprocating motion has to be electrically produced, the use of a rotary electric motor with a suitable transmission is really a rather roundabout way of solving the problem [8]. It is generally a better solution to look for an incremental-motion system with magnetic coupling, so-called "electromagnetic vibratory actuator" (EVA), which produces a direct "to-and-from" movement. Electromagnetic drives offer easy and simple control for the mass flow conveying materials. In comparison to all previously mentioned drives, these have a more simple construction and they are compact, robust, and reliable in operation. The absence of wearing mechanical parts, such as gears, cams belts, bearings, eccentrics, or motors, makes vibratory conveyors and vibratory feeders most economical equipment [9]-[13].

Application of electromagnetic vibratory drive in combination with the power converter provides flexibility during work. It is possible to provide operation of the vibratory conveying system (VCS) in the region of the mechanical resonance. Resonance is highly efficient, because large output displacement is provided by small input power. In this way, the whole conveying system has a behavior of the controllable mechanical oscillator [14], [15].

Silicon-controlled rectifier (SCR) converters are used for the EVA standard power output stage. Their usage implies a phase angle control [14]-[16] in full-wave and half-wave modes. Varying firing angle provides the controlled ac or dc injection current to control mechanical oscillations amplitude, but not the tuning of their frequency. Since conventional SCR controller operates at a fixed frequency, the vibratory mechanism must be retuned. Another way of producing a sine full-wave (or 


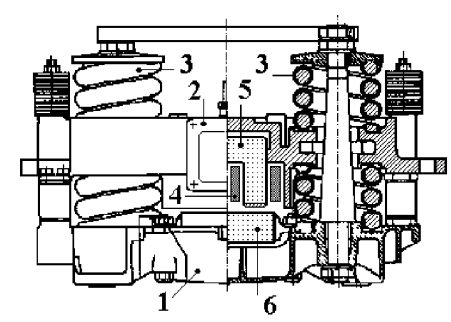

(a)

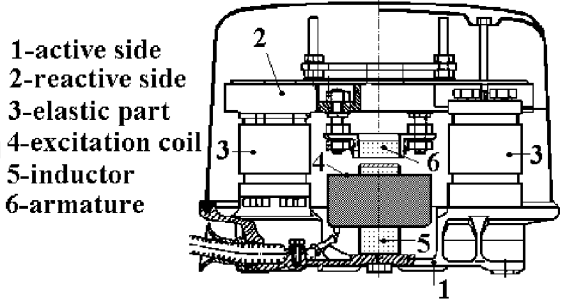

(b)

Fig. 1. Constructions of the conventional EVA. (a) Inductor on reactive side. (b) Inductor on active side.

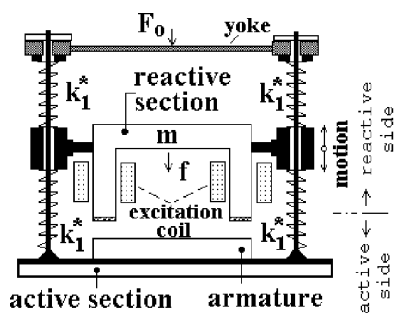

(a)

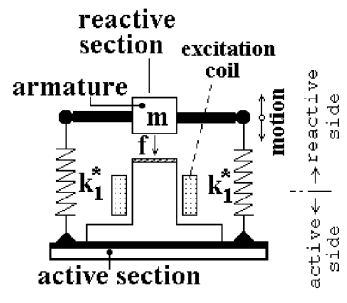

(b)
Fig. 2. Simplified EVA presentations. (a) Inductor on reactive side. (b) Inductor on active side.

half-wave) injection current is to use switch-mode power converters. Only then, driving for EVA does not depend on mains frequency. It is possible to adjust the frequency, amplitude, and duration of EVA coil current, i.e., frequency and pulse intensity of the excitation force, to be applied on the LCE.

Change of the mechanical resonant frequency, due to change of the conveying material mass, or even change of the spring stiffness, reduces efficiency of vibratory drive. An optimal and efficient operation requires tracking of resonant frequency. Consequently, complicated mechanical tuning is eliminated and electronics replace mechanical settings [17].

Previously mentioned facts were motivation for mathematical model formulation and for further research of both the phase angle control and switch mode control behavior for the electromagnetic vibratory conveying drive. Simulations and experimental results and their comparisons are exposed in this paper. The simulation model and results are given in the program package PSPICE. Experimental results are recorded on the implemented control systems for SCR and transistor power converters.

\section{Electromagnetic Vibratory ACTUATOR (EVA)}

All main types of vibratory actuators can be seen as two-mass systems. The majority of them generate harmonic excitation forces, while some types generate transmitting impact pulses. The EVA can be single- or double-stroke construction. In the single-stroke type, there is an electromagnet, whose armature is attracted in one direction, while the reverse stroke is completed by restoring elastic forces. In the two-stroke type, two electromagnets, which alternately attract the armature in different directions, are used.

In Fig. 1, two of the most common single-stroke constructions are shown. One of them has armature on its active side, while

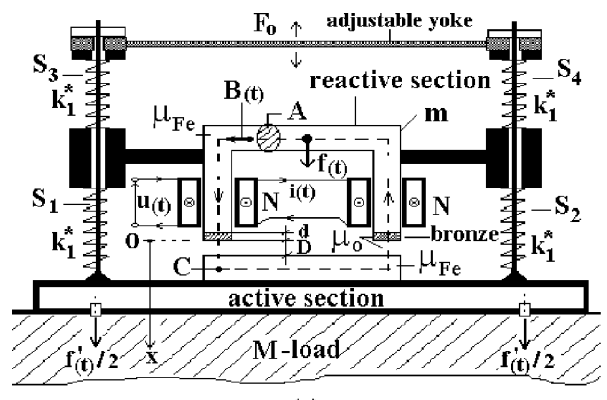

(a)

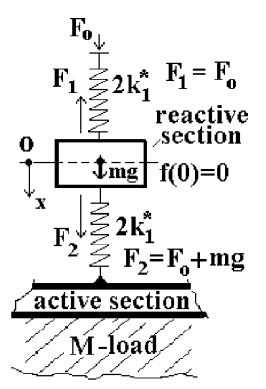

(b)
Fig. 3. EVA presentation for analysis. (a) Electromechanical model. (b) Equivalent mechanical model at $t=0$.

the inductor is on its reactive side, as shown in Fig. 1(a). The other construction is set vice versa, as shown in Fig. 1(b).

Simplified constructions of the above-mentioned vibratory actuators are shown in Fig. 2.

The mathematical model of EVA is based on presentation in Figs. 2(a) and 3 with details. An electromagnet is connected to an ac source and the reactive section is mounted on an elastic system of springs. During each half period when the maximum value of the current is reached, the armature is attracted, and at a small current value it is repelled as a result of the restoring elastic forces in springs. Therefore, vibratory frequency is double frequency of the power supply. These reactive vibrators can also operate on interrupted pulsating (dc) current. Their frequency in this case depends on the pulse frequency of the dc. A mechanical force, which is a consequence of this current and created by electromechanical conversion in the EVA, is transmitted through the springs to the LCE.

It is assumed that the mass of load $M$ is much greater than the mass $m$ of a movable reactive section. Let us suppose that springs are identically constructed, with stiffness $k_{1}^{*}$ and prestressed with action adjustable force $F_{0}$. This force is used for setting the air gap value in the actuator. The nonlinearity of spring elements is neglected. Total equivalent damping coefficient of system springs is $\beta$. The movement of the inductor is restricted in the $x$-direction. At $t=0$ (initial moment), gravitational force is compensated by spring forces $\left(F_{1}, F_{2}\right)$, as in Fig. 3(b).

It is supposed that the ferromagnetic material has a very high permeability $\mu_{\mathrm{Fe}}$ (the reluctance of the magnetic core path can be ignored) compared to $\mu_{0}$ of the air gap and bronze disk. Consequently, all the energy of the magnetic field is stored in the air gap and bronze. The area of cross section of the air gap is $A$. 
The air gap length in the state of static equilibrium is $D$. The bronze disk with thickness $d$ does not permit the inductor to form a complete magnetic circuit of iron; in other words, it inhibits "gluing" of the inductor, which is undesirable. Fringing and leakage at the air gap can be neglected too. In order to reduce eddy currents loss, the magnetic core is laminated. Also, the magnetic circuit operation in the linear region of $B(H)$ magnetization curve, with adequate limitation of the current value, is assumed. Excitation coils are connected to the voltage source $u(t)$. The source has its own resistance $R_{s}$, while the excitation coils (hereafter termed "coil") have their own resistance $R_{c}$. The current in the $2 N$-turns excitation coil is noted as $i(t)$.

Ampere's law for the reference direction of path $C$, as shown in Fig. 3(a), will be applied according to the following equation:

$$
H_{x} \cdot(D-x)+H_{b} \cdot d=N \cdot i
$$

with $H_{x}$-magnetic intensity in air gap and $H_{b}$-magnetic intensity in bronze. The flux density is

$$
B=\mu_{0} \cdot H_{x}=\mu_{0} \cdot H_{b} .
$$

Substituting this expression into (1), the flux density is

$$
B=\frac{\mu_{o} \cdot N \cdot i}{D+d-x} .
$$

The flux in bronze and air gap is

$$
\Phi=B \cdot A=\frac{\mu_{o} \cdot N \cdot A \cdot i}{D+d-x} .
$$

The total flux is

$$
\lambda(\dot{q}, x)=2 \cdot N \cdot \Phi=\frac{2 \cdot \mu_{o} \cdot N^{2} \cdot A \cdot i}{D+d-x} .
$$

The state function of the magnetic coenergy is

$$
W_{m}^{*}=\int_{0}^{i} \lambda(i, x) d i .
$$

The solution of this integral is

$$
W_{m}^{*}(i, x)=\frac{\mu_{o} \cdot N^{2} \cdot A \cdot i^{2}}{(D+d-x)} .
$$

The total system coenergy is

$$
\frac{1}{2} m \dot{x}^{2}+W_{m}^{*}(i, x) .
$$

Equation (7) can be usefully shown as

$$
W_{m}^{*}(i, x)=a \cdot \frac{i^{2}}{D+d-x}
$$

where constant $a$ is

$$
a=\mu_{0} \cdot N^{2} \cdot A .
$$

The function of the system potential energy can be shown as

$$
A_{p}=4 \cdot \frac{1}{2} k_{1}^{*} \cdot x^{2}+\left(F_{0}+m g\right) \cdot x-F_{0} \cdot x=\frac{1}{2} \cdot k \cdot x^{2}+m g \cdot x
$$

where the state function of the electrical energy is zero, because there is no accumulative electrostatic energy in the system. Based on the previous equations, Lagrange's function state for the EVA can be written as

$$
\begin{aligned}
L(\dot{x}, x, i) & =\frac{1}{2} m \cdot \dot{x}^{2}+\frac{a \cdot i^{2}}{D+d-x}-A_{p} \\
& =\frac{1}{2} m \cdot \dot{x}^{2}+\frac{a \cdot i^{2}}{D+d-x}-\frac{1}{2} \cdot k \cdot x^{2}-m g \cdot x .
\end{aligned}
$$

Rayleigh's dissipate function is defined by the following relation:

$$
R(\dot{x}, i)=\frac{1}{2} \beta \cdot \dot{x}^{2}+\frac{1}{2}\left(R_{s}+R_{c}\right) \cdot i^{2} .
$$

A dynamical equation of motion for mechanical subsystem with usage of Lagrange's equation can be presented as

$$
\frac{d}{d t}\left[\frac{\partial L(\dot{x}, x, i)}{\partial \dot{x}}\right]-\frac{\partial L(\dot{x}, x, i)}{\partial x}+\frac{\partial R(\dot{x}, i)}{\partial \dot{x}}=F_{x}
$$

where external action $F_{x}$ is the gravitational force $\left(F_{x}=m g\right)$.

From (12)-(14), the equation of motion for a mechanical subsystem becomes

$$
m \ddot{x}+\beta \cdot \dot{x}+k \cdot x=\frac{a \cdot i^{2}}{(D+d-x)^{2}} .
$$

The term on the right side of the (15) presents electromagnetic excitation force $f(t)$. This force is the function of the coil current $i$ and displacement $x$. A dynamical equation of motion for electromagnetic subsystem is obtained in a similar way deriving from

$$
\frac{d}{d t}\left[\frac{\partial L(\dot{x}, x, i)}{\partial i}\right]-\frac{\partial L(\dot{x}, x, i)}{\partial i}+\frac{\partial R(\dot{x}, i)}{\partial i}=F_{q}
$$

where external electrical action is $F_{q}=u(t)$. From (12), (13), and (16), the equation of electromagnetic subsystem becomes

$$
\frac{2 a}{D+d-x} \cdot \frac{d i}{d t}+\left(R_{s}+R_{c}\right) \cdot i+\frac{2 a \cdot i \cdot \dot{x}}{(D+d-x)^{2}}=u(t) .
$$

The first term of (17) is voltage that has been induced from current change in the circuit of the coil. Inductance of the circuit is the function of the inductor's position. The second term presents voltage drop on the equivalent resistance. The third term is actually induced electromotive force, which is a consequence of exertion of the mechanical subsystem on the electromagnetic subsystem.

Equations (15) and (17) describe the motion and electrical behavior of the EVA.

\section{Mathematical Model of THE VCS}

Electromagnetic VCSs are divided into two types: single-drive and multidrive. The single-drive systems can be one-, two-, and three-mass; the multiple-drive systems can be one- or multiple-mass [1]. A description of one type single-drive two-mass electromagnetic vibratory conveyor is shown in Fig. 4(a). Its main components are the LCE, to which the active section of the EVA is attached, comprising an active section and reactive section, with built-in elastic 

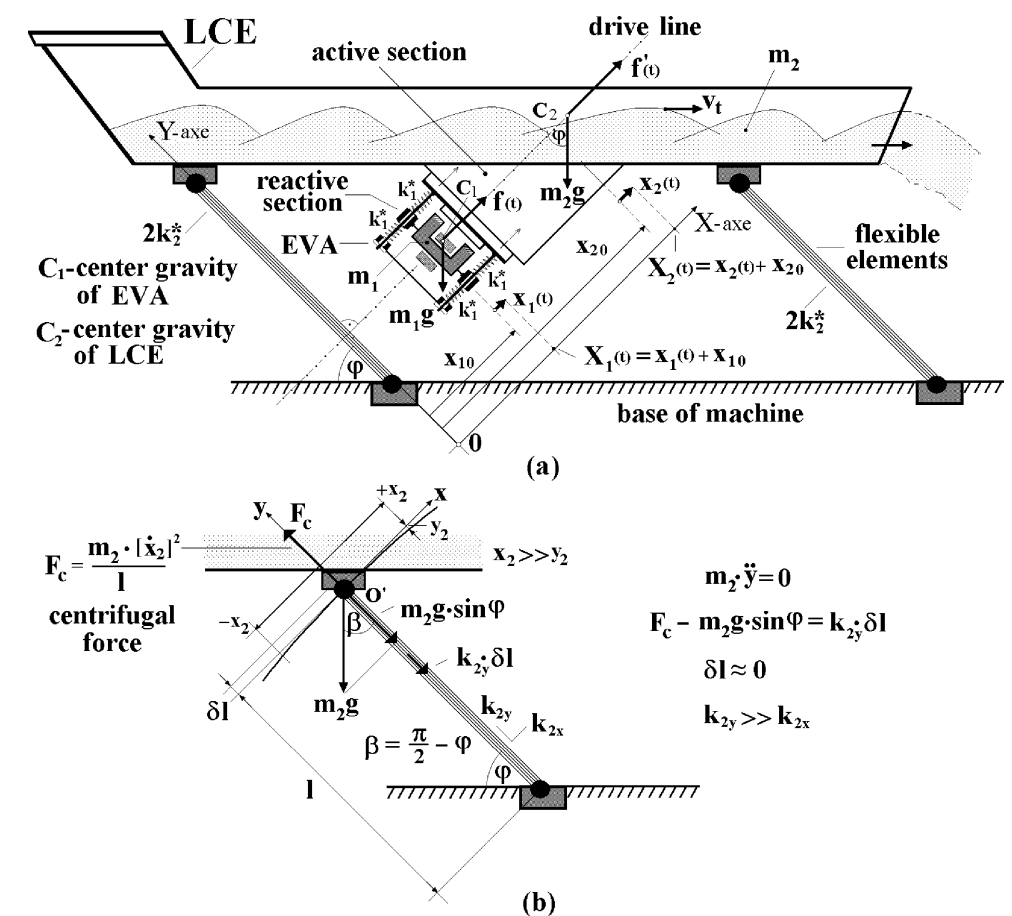

Fig. 4. Two-mass vibratory conveyor with plate springs. (a) Electromechanical model. (b) Static equilibrium forces in $y$-direction.

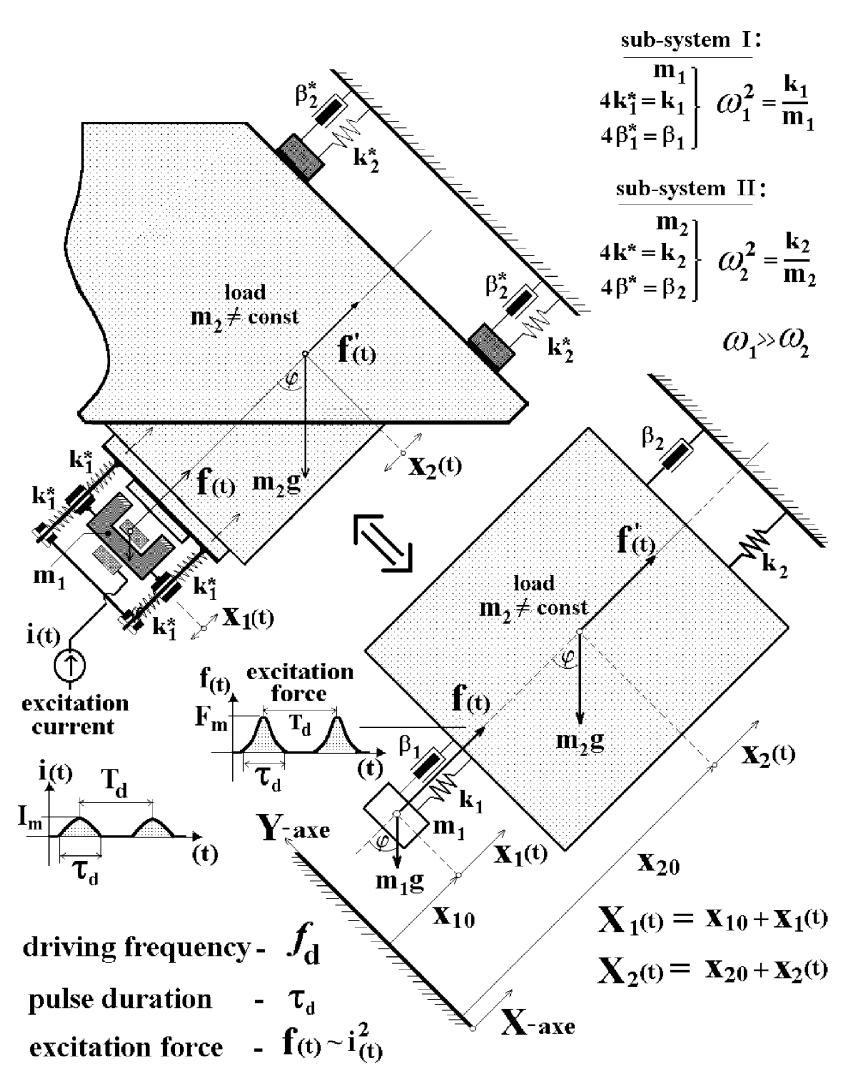

Fig. 5. Model of the VCS for analysis.

connection. Flexible elements, by which the LCE with material is supported, are composed of several leaf springs, i.e., plate springs. These elements are rigidly connected with the LCE on their one side, while on the other side, they are fitted to the base

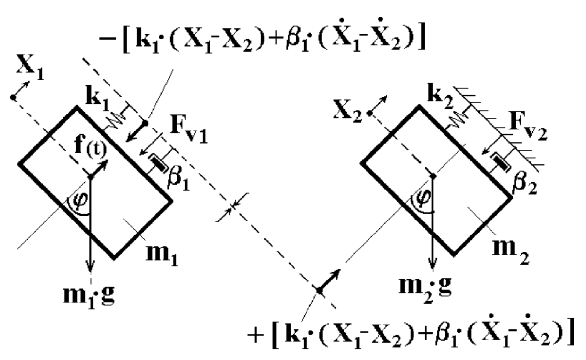

(a)

Fig. 6. Simplification of the VCS. (a) Subsystem I. (b) Subsystem II.

of the machine and sloped down under angle $\varphi$. The described construction is used in further analysis.

Referent direction of the $x$ axis is normal to the flexible elements. It is assumed that oscillations are made under excitation of the electromagnetic force $f(t)$ in the $x$-direction. This model takes into consideration only the linear characteristic of the flexible elements. Moreover, the system starts with oscillations from the state in which the static equilibrium already exists between gravitational force and the spring forces.

Oscillatory displacement is a relatively small excursion with respect to its value at a point of static equilibrium of the system. Therefore, displacement of the LCE in the $y$-direction is much less than displacement in the $x$-direction, as shown in Fig. 4(b). The flexible elements construction is such that strain of leaf springs in the $y$-direction $\left(\Delta l_{y} \approx 0\right)$ can be neglected too. In other words, it is assumed that the $y$-component of stiffness is much greater than the $x$-component of stiffness. Centrifugal force $F_{c}$ is compensated by the component of gravitation force $m_{2} \cdot g \cdot \sin \varphi$.

Given the assumptions above, this construction is a system with two degrees of freedom, which is shown in Fig. 5. The 


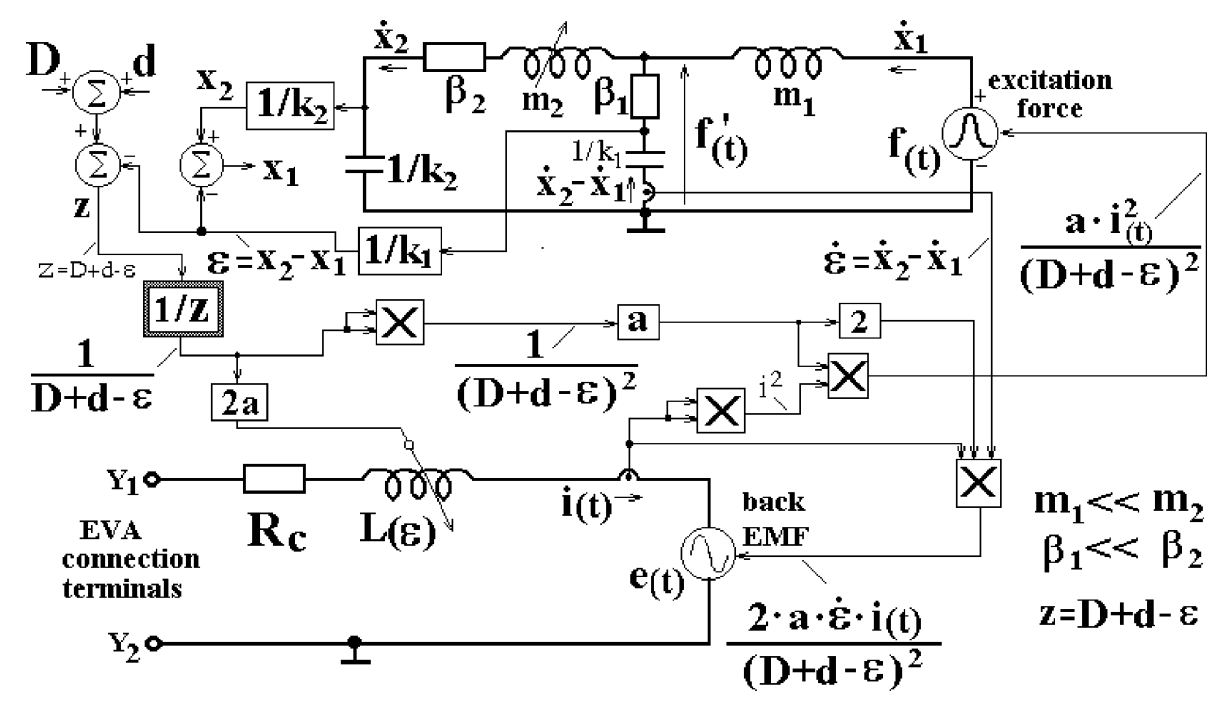

Fig. 7. Simulation circuit of the VCS.

system will be analyzed as follows: the mass of the EVA reactive section is presented by $m_{1}$, while the mass $m_{2}$ constitutes a sum of masses (the LCE, conveying material, and the active section of EVA). The mass $m_{2}$ is a variable parameter within the system, because mass of the conveying material is varied under real conditions. Equivalent stiffness of springs within the EVA is denoted as $k_{1}$, while equivalent $x$-component stiffness of plate springs is denoted as $k_{2}$. Coefficient $\beta_{1}$ describes mechanical losses and damping of the reactive part in EVA, while $\beta_{2}$ is the equivalent damping coefficient within the transporting system (the LCE with material). Generally, damping coefficients can be presented as a compound function of mass and stiffness $\beta=$ $\beta(k, m)$. Some authors deal with the linear function, $\beta=a$. $m+b \cdot k$ ( $a$ and $b$ are tuning parameters for damping coefficient) [14], [15].

Displacements of both masses $m_{1}$ and $m_{2}$ within the oscillatory system are described as $X_{1}=x_{10}+x_{1}$, and $X_{2}=x_{20}+x_{2}$, as in Fig. 5. Variables $x_{10}$ and $x_{20}$ are the initial positions of oscillating masses $m_{1}$ and $m_{2}$.

In order to achieve a dynamic model of this system, the whole system is divided in two subsystems, as shown in Fig. 6.

Including in consideration the mass $m_{1}$ and its effect on the rest of the system by force: $-\beta_{1} \cdot\left(\dot{X}_{1}-\dot{X}_{2}\right)-k_{1} \cdot\left(X_{1}-X_{2}\right)$, as in Fig. 6(a), dynamic equation of motion in this case is formulated as

$$
\begin{aligned}
m_{1} \cdot \ddot{X}_{1}=-m_{1} \cdot g \cdot \cos \varphi- & \beta_{1} \cdot\left(\dot{X}_{1}-\dot{X}_{2}\right) \\
& -k_{1} \cdot\left(X_{1}-X_{2}\right)+f(t) .
\end{aligned}
$$

Due to $\ddot{x}_{10}=0$ and $\dot{x}_{10}=\dot{x}_{20}=0,(18)$ can be written as

$$
\begin{array}{r}
m_{1} \cdot \ddot{x}_{1}=-m_{1} \cdot g \cdot \cos \varphi-\beta_{1} \cdot\left(\dot{x}_{1}-\dot{x}_{2}\right)-k_{1} \cdot\left(x_{10}-x_{20}\right) \\
-k_{1} \cdot\left(x_{1}-x_{2}\right)+f(t) .
\end{array}
$$

In the state of static equilibrium $m_{1} \cdot g \cdot \cos \varphi=k_{1} \cdot\left(x_{20}-x_{10}\right)$, $\dot{x}_{10}-\dot{x}_{20}=0$ and $f(0)=0$, the above equation becomes

$$
m_{1} \ddot{x}_{1}=-\beta_{1} \cdot\left(\dot{x}_{1}-\dot{x}_{2}\right)-k_{1} \cdot\left(x_{1}-x_{2}\right)+f(t) .
$$

TABLE I

EVA PARAMETERS USED IN THE SIMULATIONS

\begin{tabular}{|c||l|}
\hline electrical & mechanical \\
\cline { 2 - 2 } $\mathrm{R}_{\mathrm{c}}=4.8 \Omega$ & $\mathrm{D}=8 \mathrm{~mm}$ \\
$\mathrm{~L}(\mathrm{x}=0)=175 \mathrm{mH}$ & $\mathrm{d}=1 \mathrm{~mm}$ \\
$\mathrm{a}=8 \cdot 10^{-3} \mathrm{Am}$ & $\mathrm{m}_{1}=0.5 \mathrm{~kg}$ \\
& $\mathrm{k}_{1}=30 \mathrm{kH} / \mathrm{mm}$ \\
& $\hat{\beta}_{1}=0.1 \mathrm{~N} / \mathrm{m} / \mathrm{s}$ \\
\hline
\end{tabular}

TABLE II

VIBRATORY CONVEYOR PARAMETERS USED IN THE SIMULATIONS

$$
\begin{array}{|l|}
\hline \mathrm{m}_{2}=0 \ldots 150 \mathrm{~kg} \\
\hline \mathrm{k}_{2}=10 \mathrm{kN} / \mathrm{mm} \\
\hline \beta_{2}=1200 \mathrm{~N} / \mathrm{m} / \mathrm{s} \\
\hline
\end{array}
$$

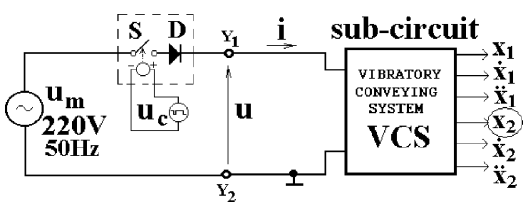

Fig. 8. Simulation circuit of power converter with phase control.

Including in consideration the mass $m_{2}$ and its effect on the rest of the system with force $\beta_{1} \cdot\left(\dot{X}_{1}-\dot{X}_{2}\right)+k_{1} \cdot\left(X_{1}-X_{2}\right)$, as in Fig. 6(b), the differential equation in this case is described as

$$
\begin{array}{rl}
m_{2} \cdot \ddot{X}_{2}=-m_{2} \cdot g & g \cdot \cos \varphi-\beta_{2} \cdot \dot{X}_{2}-k_{2} \cdot X_{2} \\
& +k_{1} \cdot\left(X_{1}-X_{2}\right)+\beta_{1} \cdot\left(\dot{X}_{1}-\dot{X}_{2}\right) .
\end{array}
$$

Considering $\ddot{x}_{20}=\dot{x}_{20}=0$ and $\dot{x}_{10}-\dot{x}_{20}=0$, (21) can be written as

$$
\begin{array}{r}
m_{2} \cdot \ddot{x}_{2}=-m_{2} \cdot g \cdot \cos \varphi-\beta_{2} \cdot \dot{x}_{2}-k_{2} \cdot x_{2}+k_{1} \cdot\left(x_{1}-x_{2}\right) \\
+\beta_{1} \cdot\left(\dot{x}_{1}-\dot{x}_{2}\right)+k_{1} \cdot\left(x_{10}-x_{20}\right)-k_{2} \cdot x_{20} .
\end{array}
$$



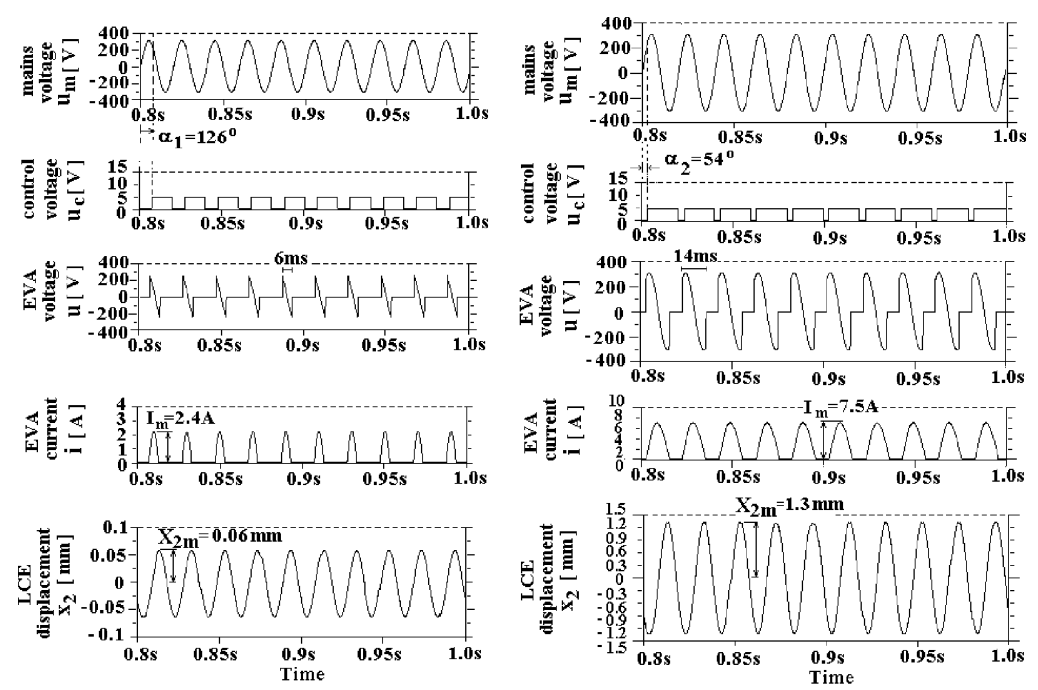

(a)

(b)

Fig. 9. Characteristic waveforms in case of phase control. (a) Phase angle $\alpha_{1}=126^{\circ}$. (b) Phase angle $\alpha_{2}=54^{\circ}$.

In the state of static equilibrium $m_{2} \cdot g \cdot \cos \varphi=k_{2} \cdot x_{20}+k_{1} \cdot$ $\left(x_{10}-x_{20}\right)$, the above equation becomes

$$
m_{2} \ddot{x}_{2}=-\beta_{2} \dot{x}_{2}-k_{2} x_{2}+k_{1} x_{1}-k_{1} x_{2}+\beta_{1} \cdot\left(\dot{x}_{1}-\dot{x}_{2}\right) \text {. }
$$

From the electrical equation (17) for EVA (by substituting $\left.x \rightarrow x_{2}-x_{1} ; \dot{x} \rightarrow \dot{x}_{2}-\dot{x}_{1}\right)$ and from the derived equations (20) and (23), which are related to a previously presented model of the conveying drive, results the final form of dynamical equations of the VCS

$$
\begin{gathered}
m_{1} \ddot{x}_{1}+\beta_{1} \cdot\left(\dot{x}_{1}-\dot{x}_{2}\right)+k_{1} \cdot\left(x_{1}-x_{2}\right)=f(t) \\
m_{2} \ddot{x}_{2}+\beta_{2} \dot{x}_{2}+\left(k_{1}+k_{2}\right) x_{2}-k_{1} x_{1} \\
-\beta_{1} \cdot\left(\dot{x}_{1}-\dot{x}_{2}\right)=0 \\
\frac{2 a}{D+d-\left(x_{2}-x_{1}\right)} \cdot \frac{d i}{d t}+\left(R_{s}+R_{c}\right) i \\
+\frac{2 a \cdot i \cdot\left(\dot{x}_{2}-\dot{x}_{1}\right)}{\left[D+d-\left(x_{2}-x_{1}\right)\right]^{2}}=u(t) \\
f(t)=\frac{a \cdot i^{2}}{\left[D+d-\left(x_{2}-x_{1}\right)\right]^{2}} .
\end{gathered}
$$

The whole system is described by three differential equations. Differential equations (24) and (25) describe mechanical behavior of the system under time-variable excitation electromagnetic force $f(t)$, which is a consequence of coil current $i(t)$. The third equation is (26), for coil electrical equilibrium.

\section{Simulation Circuit}

Simulation circuit of the VCS is created on the basis of previously derived differential equations. A functional diagram is shown in Fig. 7, upon which the simulation model is based. Mechanical quantities are shown with equivalent electric quantities according the table of electromechanical analogs for inverse system [18].

A simulation model is generated in the program package PSPICE and a subcircuit is formed for application within

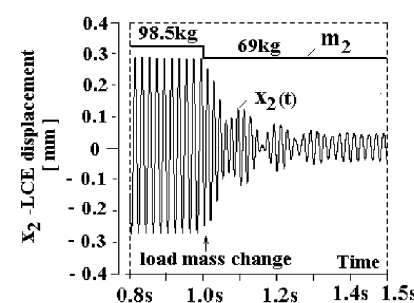

(a)

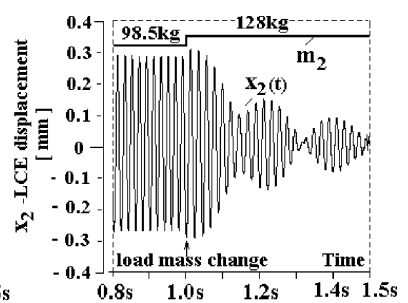

(b)
Fig. 10. Influences of the conveying mass change to amplitude oscillation. (a) Decrease conveying mass. (b) Increase conveying mass.

different simulation diagrams, when analyzing various types of power converters for electromagnetic vibratory drive.

\section{Simulation Results}

In this section, simulation results for cases of phase angle control and switch-mode current control are presented. $\mathrm{Pa}$ rameters of the real actuator and vibratory system are chosen. Electrical and mechanical parameters of the EVA are given in Table I, while mechanical parameters of the conveyor are given in Table II.

In the following text, behavior of the system operating in a stationary state and transient regimes with varying conveying mass $m_{2}$ is described.

\section{A. Phase Control}

Simulation circuit with phase angle control of the EVA coil is given in Fig. 8. The load mass, which is oscillating, is $m_{2}=$ $98.5 \mathrm{~kg}$. It has been taken that the mechanical natural frequency $f_{\text {res }}$ of the system is equal to mains (ac source) frequency $f=$ $50 \mathrm{~Hz}$. Power SCR is simulated as voltage-controlled switch $S$, with diode $D$ in series. The conducting moment of the switch is determined by the control voltage, synchronized with the moment of mains voltage zero-cross and phase shifted for angle $\alpha$.

Simulation results for phase angles $\alpha_{1}=126^{\circ}$ and $\alpha_{2}=$ $54^{\circ}$ are shown in Fig. 9(a) and (b), respectively. Characteristic 

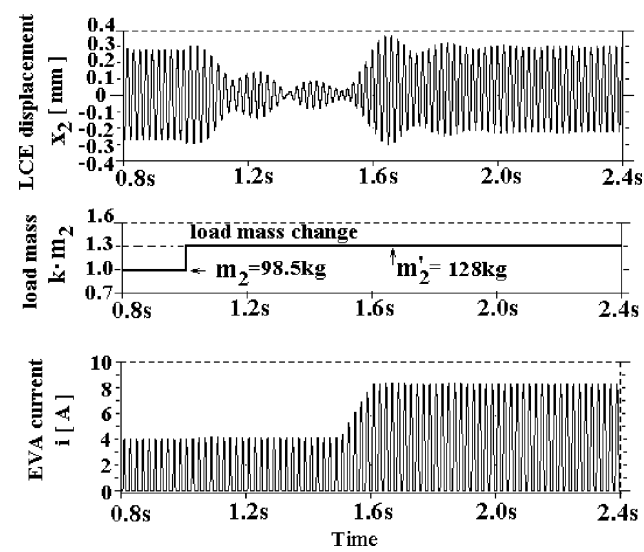

Fig. 11. Amplitude constant value keeping and conveying mass change compensation.

values are: mains voltage $u_{m}$, control voltage $u_{c}$, coil voltage $u$, coil current $i$, and the LCE displacement $x_{2}$.

It can be concluded from simulation results that the change of vibratory width is due to a change of phase angle. By decreasing phase angle, the effective voltage and coil current increase. This is caused by an increase of the oscillation amplitude of LCE too, which is created by a stronger impulse of excitation force, i.e., by entering greater energy into the mechanical oscillating system. On the other hand, an increase of phase angle causes decrease of the oscillation amplitude of LCE.

The influence of the conveying material mass changing on the amplitude oscillations at phase angle $\alpha=100^{\circ}$ is shown in Fig. 10. It has been adjusted in simulation that at the moment $t=$ $1 \mathrm{~s}$, the load mass decreases for 30\%, as shown in Fig. 10(a), and the mass load increases for 30\%, as shown in Fig. 10(b). Then, there occurs a change of the resonance frequency from $f_{1}=$ $50 \mathrm{~Hz}$ to $f_{2} \approx f_{1} \pm 10 \mathrm{~Hz}$. Changing of the load mass causes significant decrease of the oscillation amplitude. In addition, in the new stationary state, there has been distorted waveform of displacement.

In order to keep amplitude values constant, in the case of a mass $m_{2}$ increase, it will be necessary to increase energy consumption (significant current increase) from the ac source, as shown in Fig. 11. A similar conclusion can be drawn, when the conveying mass $m_{2}$ decreases.

\section{B. Switch-Mode Control}

From an electrical standpoint, the EVA is mostly inductive load by its nature, so that generating the sinusoidal half-wave current is possible by switching the converter with current-mode control. One possibility is using asymmetric half-bridge, i.e., dual forward converter, as in Fig. 12.

It is assumed that the load mass is $m_{2}=98.5 \mathrm{~kg}$ (resonant frequency is $f_{\text {res }}=50 \mathrm{~Hz}$ ). The EVA is driven from sinusoidal half-wave current, attained from tracking the reference sine halfwave with $f_{d}=50 \mathrm{~Hz}$. It has been simply realized with the comparator tolerance band, i.e., hysteresis ("bang-bang") controller. The reference current was compared with actual current with the tolerance band around the reference current. It means that controller input is defined by current feedback error signal. Half-bridge supply voltage is $V_{\text {bus }}=+400 \mathrm{~V}_{\mathrm{DC}}$.

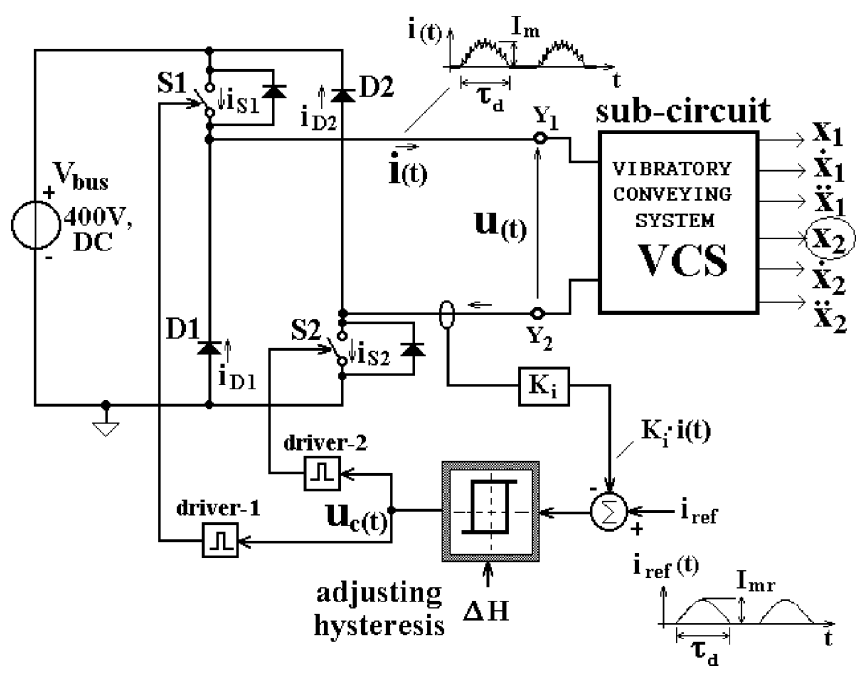

Fig. 12. Simulation circuit of power converter with switching control.

Characteristic simulation waveforms are shown in Fig. 13. Observed variables are coil current $i$, switches current $i_{S 1}, i_{S 2}$, freewheeling diodes current, $i_{D 1}, i_{D 2}$, switches control voltage $u_{c}$, coil voltage $u$, and LCE displacement $x_{2}$.

The compensation of load mass change (i.e., mechanical resonant frequency change) is achieved by tuning the amplitude and the current frequency of EVA. From the moment of load mass changing, it is necessary to locate the new resonant frequency upon which the oscillation amplitude is being tuned. The resonant frequency seeking process of the VCS and the amplitude oscillation tuning are given in Fig. 14.

In order to present the above-mentioned process in more detail, the whole time interval for the resonant frequency seeking process and the LCE amplitude oscillation adjusting is divided in seven time intervals (I-VII). In the first time interval, the driving frequency is tuned oN $f_{d}=50 \mathrm{~Hz}$. In subinterval (0.5-0.6 s), which is presented in Fig. 15(a), the load mass was $98.5 \mathrm{~kg}$, while the LCE amplitude oscillation was $X_{2 m}=0.5 \mathrm{~mm}$. In the mentioned subinterval, the driving frequency is equal to the mechanical resonant frequency. The waveform of LCE displacement is sinusoidal with a frequency of $f=50 \mathrm{~Hz}$. From the moment $t_{1}=0.6 \mathrm{~s}$, the load mass is being abruptly decreased to $67.5 \mathrm{~kg}$, so that the mechanical resonant and driving frequency become unequal. This induces significant distortion of the LCE displacement and amplitude oscillation decreases.

A decrease of driving current frequency to $45 \mathrm{~Hz}$, with its constant amplitude $\left(I_{m}=4.8 \mathrm{~A}\right)$ in the moment $t_{2}=1 \mathrm{~s}$, is responsible for further amplitude oscillation reducing and stronger distortion of the LCE displacement, which is shown in Fig. 16(a). At the beginning of the third interval $\left(t_{3}=1.2 \mathrm{~s}\right)$, the driving current frequency is tuned on the greater value $\left(f_{d}=\right.$ $55 \mathrm{~Hz}$ ). From that moment, the LCE amplitude oscillation is increased to $0.2 \mathrm{~mm}$ and the LCE displacement distortion is decreased, as shown in Fig. 16(b). At the beginning of the fourth interval $\left(t_{4}=1.4 \mathrm{~s}\right)$, the frequency of driving current is increased to $\left(f_{d}=60 \mathrm{~Hz}\right)$, with its constant amplitude. In this time interval, the LCE amplitude oscillation is increased to 0.3 

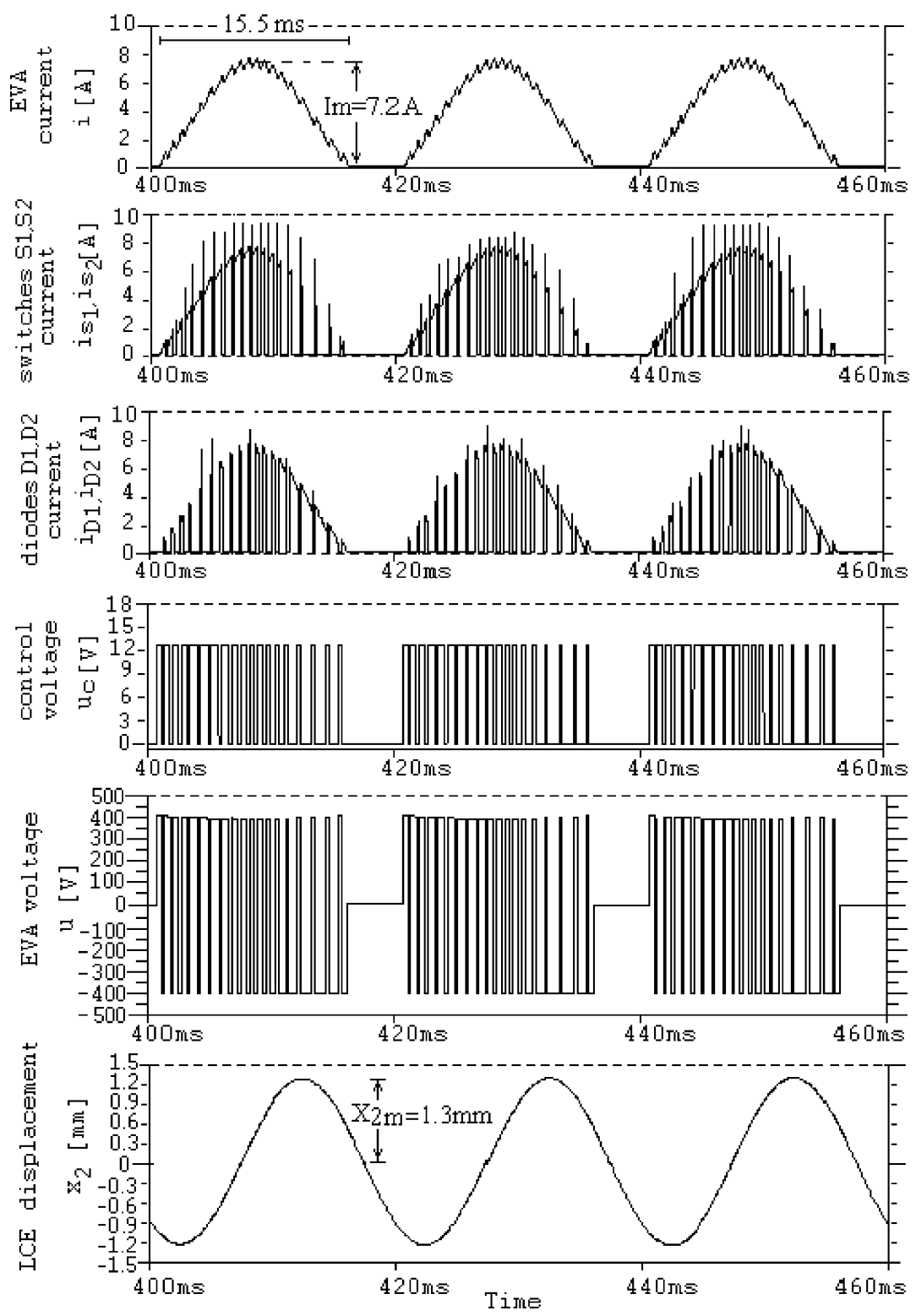

Fig. 13. Characteristic waveforms in the case of switching control.

$\mathrm{mm}$ and distortion of the LCE displacement has almost completely disappeared, which is shown in Fig. 16(c). A further increase of the driving current frequency on $f_{d}=65 \mathrm{~Hz}$ (the fifth time interval) is attempted in the LCE amplitude oscillation decreasing and significant distortion of the LCE displacement, as shown in Fig. 16(d).

It is concluded from previous resonant frequency seeking process that the optimal operation of the VCS is achieved on the driving current frequency $f_{d}=60 \mathrm{~Hz}$, setting from the moment $t_{6}=2 \mathrm{~s}$. In the sixth interval, the LCE displacement has the same waveform, as in the fourth interval, but amplitude oscillation $\left(X_{2 m}=0.4 \mathrm{~mm}\right)$ is reduced with respect to its value at the beginning of the process.

In order to keep the LCE amplitude oscillation on the initial value of $0.5 \mathrm{~mm}$ in the moment $t_{7}=2.6 \mathrm{~s}$ (which is the beginning of the seventh interval), the driving current amplitude increase is set on about $I_{m}^{\prime}=5.3 \mathrm{~A}$, while its frequency remains constant $\left(f_{d}=60 \mathrm{~Hz}\right)$. In the new stationary state, the
LCE amplitude oscillation is $X_{2 m}^{\prime}=0.5 \mathrm{~mm}$, as at the beginning of the first interval. This case is presented in Fig. 15(b).

\section{EXPERIMENTAL RESULTS}

In this section, some experimental results are presented. These results are recorded on the real experimental control systems for the SCR and transistor power converter for driving one real electromagnetic vibratory conveyor. The LCE acceleration is measured by inductive acceleration sensor, which has B12/500-HBM type for acceleration range 0-1000 $\mathrm{m} / \mathrm{s}^{2}$ and for frequency range $0-200 \mathrm{~Hz}$. The LCE displacement is measured by noncontact inductive sensor, which has NCDT3700- $\mu$ Epsilon type for displacement range 0-6 mm and for frequency range $0-10 \mathrm{kHz}$.

\section{A. Phase Control}

A principal block diagram for implemented phase control is shown in Fig. 17. It consists of the following functional units: 

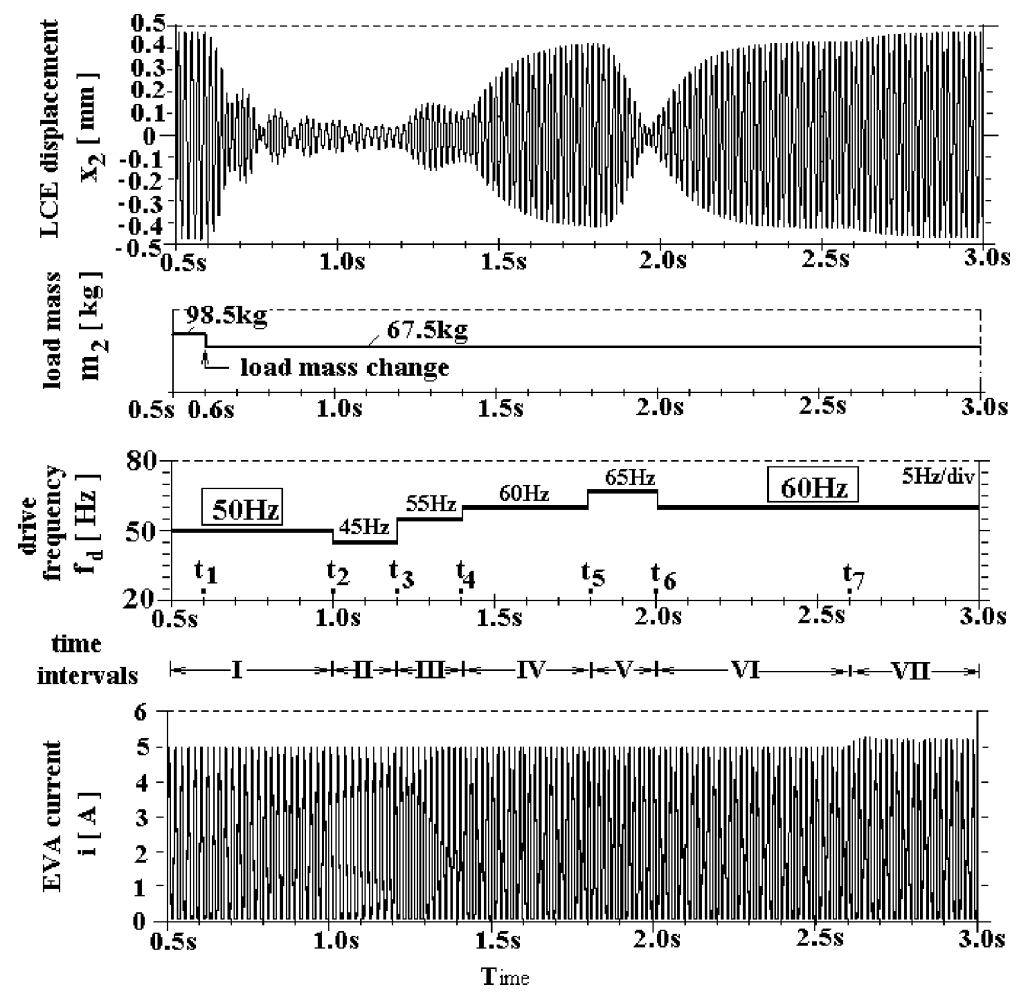

Fig. 14. Keeping the amplitude oscillation of the LCE and load change compensation.

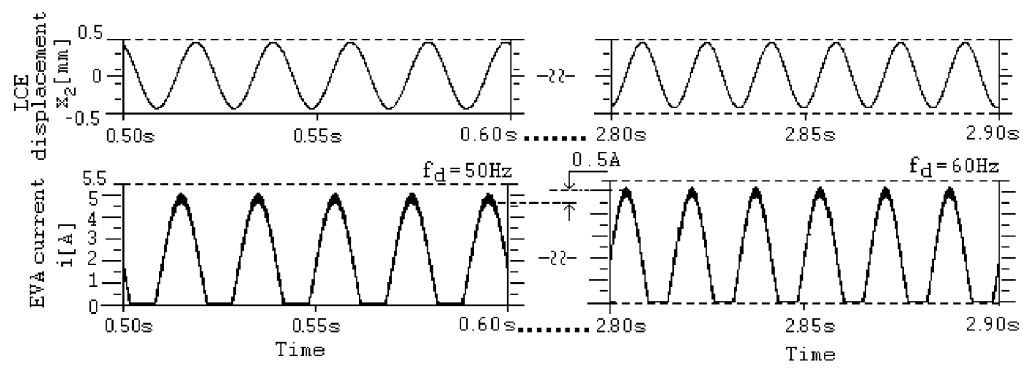

(a)

(b)

Fig. 15. LCE displacement and EVA current. (a) Time interval I. (b) Time interval VII.

power stage for driving EVA, synchronization circuit with zerocross detection, half-wave trigger pulse generator, pulse transformer for galvanic isolation control circuits from power stage, proportional-integral-differential regulator with implemented soft-start and soft stop function, potentiometer of referenced value, discriminator and measurement block for analog processing of acceleration sensor signals.

In Fig. 18(a) and (b), oscilloscopic records for EVA current and EVA voltage at firing angles $\alpha_{1}=126^{\circ}$ and $\alpha_{2}=54^{\circ}$ are shown, respectively. Mains voltage has effective value $U=$ $220 \mathrm{~V}$ and frequency $f=50 \mathrm{~Hz}$. The load mass is $m_{2}=$ $98.5 \mathrm{~kg}$. The mechanical resonant frequency is $f_{\text {res }}=50 \mathrm{~Hz}$.

In Fig. 19(a) and (b), oscilloscopic records of the LCE displacement, LCE acceleration, and EVA current at firing angles $\alpha_{1}=126^{\circ}$ and $\alpha_{2}=54^{\circ}$ are shown, respectively, according to the same oscillatory system parameters.

The experimental results, for two values firing angle, are reported in Table III. Measured variables are amplitude of EVA current $I_{m}$, duration of EVA current $\tau_{d}$, amplitude of LCE dis- placement $X_{2 m}$, vibratory width of LCE $X_{2 p-p}$, actual acceleration amplitude $a_{m}$, double acceleration amplitude $a_{2 p-p}$, and calculated acceleration amplitude $a_{m}^{*}$. The calculated acceleration amplitude for resonant frequency is given to $a_{m}^{*}=(2 \pi$. $\left.f_{\text {res }}\right)^{2} \cdot X_{2 m}=\omega_{\text {res }}^{2} \cdot X_{2 m}$.

The experimental and simulation characteristic waveforms of the VCS are corresponding. Differences in the EVA current and voltage waveforms with oscillatory character at turn off are consequences of some neglect in simulation model (real SCR characteristic, stray inductance, and capacitance of a circuit, etc.), which exist in real conditions.

The quantitative comparison between experimental and simulation results indicates that the measured characteristic values on the real model (Table III) correspond to those obtained in simulation (Fig. 9).

\section{B. Switch-Mode Control}

A block diagram for implemented ac/dc transistor converter is shown in Fig. 20. The diagram is utilized for observance of the 


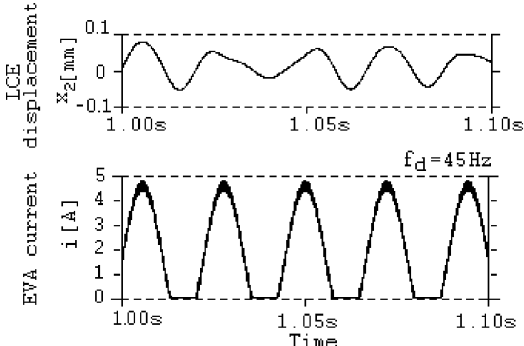

(a)

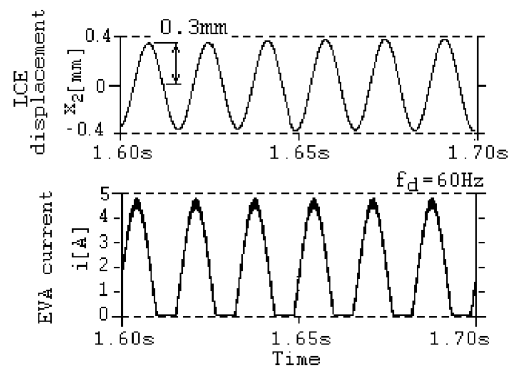

(c)

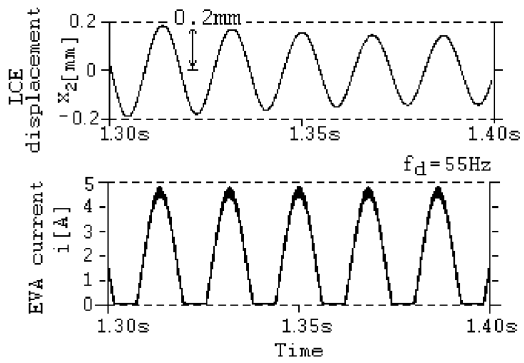

(b)

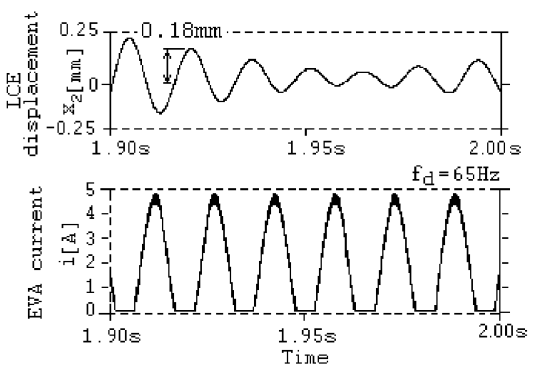

(d)

Fig. 16. LCE displacement and EVA current. (a) Time interval II. (b) Time interval III. (c) Time interval IV. (d) Time interval V.

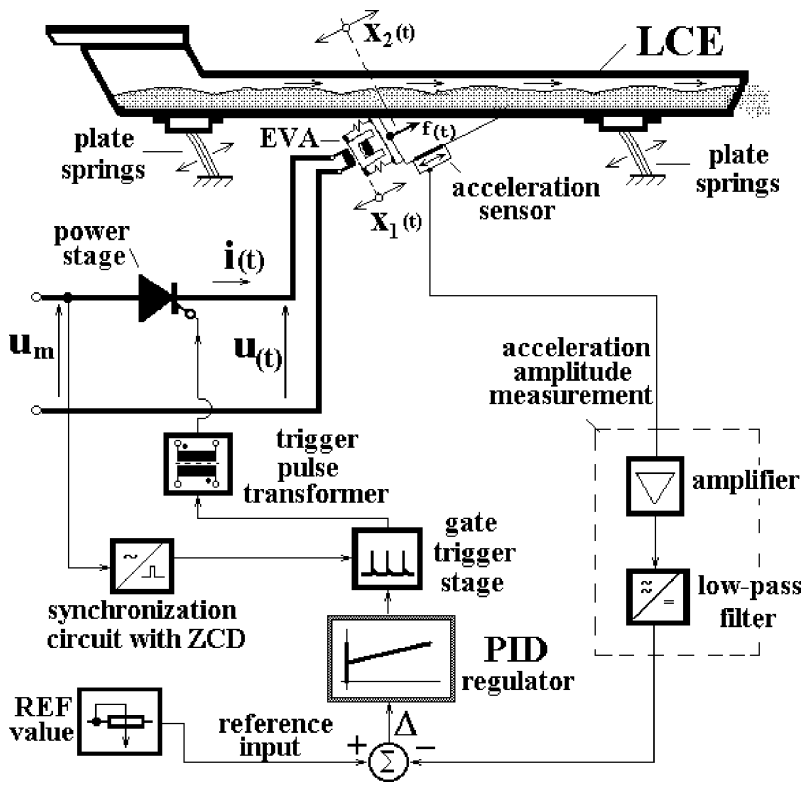

Fig. 17. Phase control block diagram.

VCS behavior according to conveying mass change. The transistor converter comprises two power converters. One is an input ac/dc converter with a power factor correction (PFC), while the other one is a dc/dc (pulsating current) converter for driving EVA. The input converter is in fact a controllable transistor rectifier with two "boost" stages and inductance on the ac side. This converter with advantages over the conventional power factor corrector (diode bridge rectifier-power switch-diode-inductance on the dc side) is described in detail in [19] and [20]. The output converter is realized with asymmetric half-bridge, i.e., dual forward converter and it consists of two IGBT, $T_{1}$ and $T_{2}$, on one bridge diagonal and two freewheeling diodes, $D_{1}$ and $D_{2}$, on the other, opposite diagonal. The drive circuit is a high voltage high-speed power IGBT driver with independent high and low side referenced output channels. The floating channel is designed for bootstrap operation, high voltage fully operational, tolerant of negative transient voltage and "dV/dt" immune. The actual EVA current is compared with the tolerance band around the reference current. The actual current is measured by the Hall effect compensated current sensor, with electrical isolation. The error signal is maintained on the comparator tolerance band input, which has the possibility for $\Delta H$-hysteresis adjusting. Output from the comparator is guided to the power transistor drive circuit.

Sine half-wave current reference value is obtained by precise rectification of signal difference from the voltage controlled oscillator and controller output. This reference value is determinated by reference inputs, $V_{x}$ for amplitude and duration and $V_{f}$ for frequency. Both of these signals are controlled by the controller, which is based on PC104 module. The difference between the actual and reference current is qualified by hysteresis width. Satisfactory modulation frequency for those mechanical systems is within the range $2-5 \mathrm{kHz}$, due to inertness of mechanical systems and they do not react to high frequency (more than $300 \mathrm{~Hz}$ ). The current frequency of the power converter output is tuned within the range $10-150 \mathrm{~Hz}$ and it is independent of mains frequency. The LCE acceleration is measured by an inductive acceleration sensor and LCE displacement is measured by a noncontact inductive sensor. These signals are normalized on the voltage level $0-10 \mathrm{~V}$ by electronic transducers, arranged for each of these sensors. The characteristic output waveforms, coming from switching converter, have been measured and recorded on the prototype, as in Fig. 21.

Oscilloscopic records of the EVA current and voltage are shown in Fig. 21(a). The EVA current amplitude and frequency are tuned on $I_{m}=7.2 \mathrm{~A}$ and $f_{d}=50 \mathrm{~Hz}$, respectively, while its duration is tuned on $\tau_{d}=15.5 \mathrm{~ms}$. Ripple of output current is about $\Delta i=0.4 \mathrm{~A}$, with variable frequency, because hysteresis 


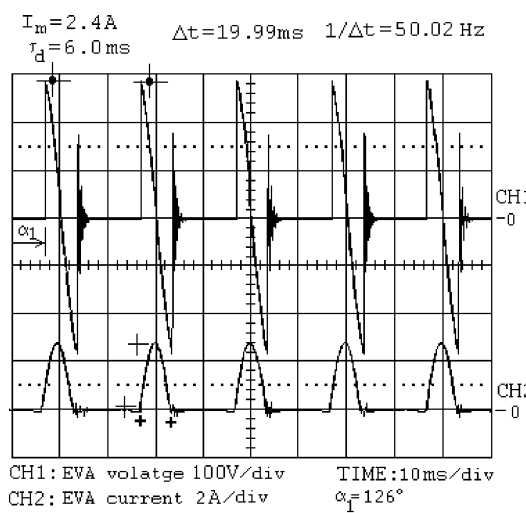

(a)

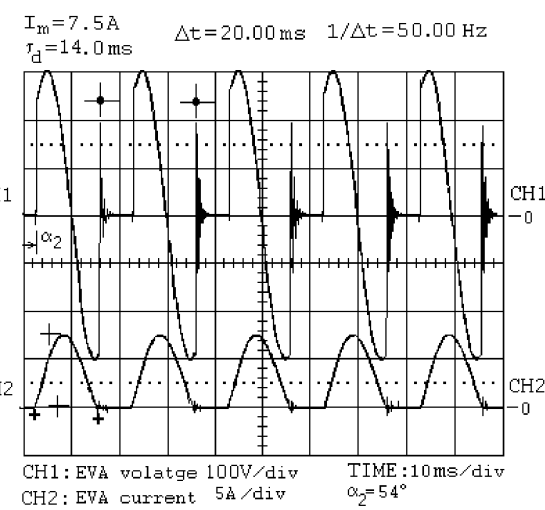

(b)

Fig. 18. Oscilloscopic records of EVA voltage and EVA current. (a) Firing angle $\alpha_{1}=126^{\circ}$. (b) Firing angle $\alpha_{2}=54^{\circ}$.

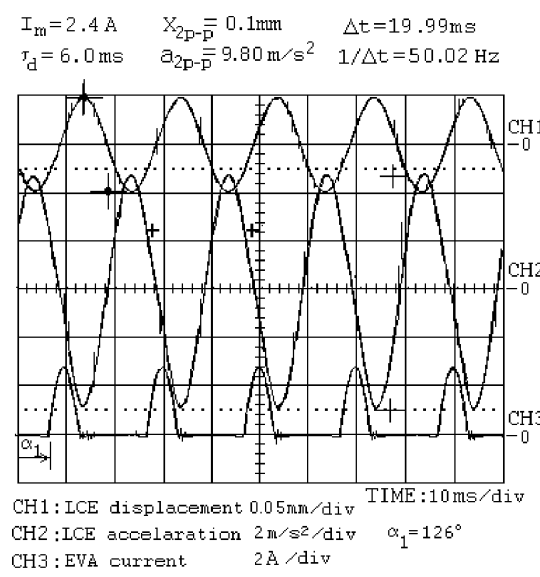

(a)

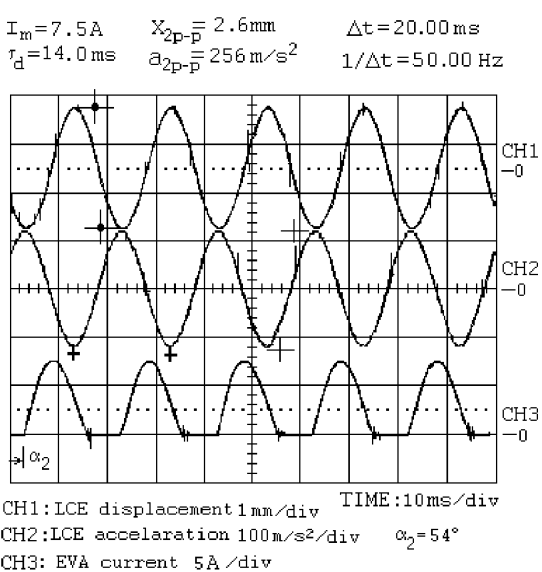

(b)

Fig. 19. Oscilloscopic records of LCE displacement, acceleration, and EVA current. (a) Firing angle $\alpha_{1}=126^{\circ}$. (b) Firing angle $\alpha_{2}=54^{\circ}$.

TABLE III

MEASUREd RESUlts FOR PHASE CONTROL

\begin{tabular}{|c|c|c|}
\hline measured values & $\alpha_{1}=126^{\circ}$ & $\alpha_{2}=54^{\circ}$ \\
\hline$I_{\mathrm{m}}[\mathrm{A}]$ & 2.4 & 7.5 \\
\hline$\tau_{\mathrm{d}}[\mathrm{ms}]$ & 6.0 & 14.0 \\
\hline $\mathrm{X}_{2 \mathrm{~m}}[\mathrm{~mm}]$ & 0.05 & 1.30 \\
\hline $\mathrm{X}_{2 \mathrm{p}-\mathrm{p}}[\mathrm{mm}]$ & 0.10 & 2.60 \\
\hline$a_{\mathrm{m}}\left[\frac{\mathrm{m}}{\mathrm{s}^{2}}\right]$ & 5.0 & 128.0 \\
\hline$a_{2 \mathrm{p}-\mathrm{p}}\left[\frac{\mathrm{m}}{\mathrm{s}^{2}}\right]$ & 9.80 & 256.0 \\
\hline$a_{\mathrm{mi}}^{*}\left[\frac{\mathrm{m}}{\mathrm{s}^{2}}\right]$ & 4.93 & 128.40 \\
\hline
\end{tabular}

value is preset. The highest ripple frequency $\left(f_{r} \approx 2 \mathrm{kHz}\right)$ is for maximum current.

Oscilloscopic records of the EVA current, LCE displacement, and acceleration are shown in Fig. 21(b). At driving frequency $f_{d}=f_{\text {res }}=50 \mathrm{~Hz}$, "peak-to-peak" acceleration amplitude is $a_{2 p-p}=256 \mathrm{~m} / \mathrm{s}^{2}$, which is corresponding to the vibratory width of $X_{2 p-p}=2.6 \mathrm{~mm}$. It is easy to check with simulation waveforms in Fig. 13. The LCE acceleration waveform has smooth sinusoidal characteristics, although the EVA current half-wave does not have the form of an ideal sinusoidal function.

The resonant frequency seeking process and system response (conveying mass acceleration) is represented by oscilloscopic records, shown in Fig. 22.

Conveying mass is adjusted to $m_{2}=67 \mathrm{~kg}$. The current half-wave pilot signal is set on amplitude $I_{m}=4.8 \mathrm{~A}$. Signal duration is $\tau_{d}=8 \mathrm{~ms}$, from the highest frequency $f_{d(\text { high })}=$ $200 \mathrm{~Hz}$ to the lowest frequency $f_{d(\text { low })}=10 \mathrm{~Hz}$, with step frequency $\Delta f=5 \mathrm{~Hz}$. Total lookup time is about $5 \mathrm{~s}$. The record is referred to a frequency range $100-45 \mathrm{~Hz}$. Considering the significant acceleration amplitude increase, there are three marked sections (I, II, III). Each section is shown in detail in Fig. 23.

Section I is presented in Fig. 23(a). Taken that the acceleration amplitude $a_{2 m}=31 \mathrm{~m} / \mathrm{s}^{2}\left(a_{2 p-p}=62 \mathrm{~m} / \mathrm{s}^{2}\right)$ and the value of EVA current frequency $f_{\mathrm{dI}}=65 \mathrm{~Hz}$, the acceleration waveform seems to be distorted, but it resembles sinusoidal. It is assumed, also, that the resonant frequency is closed to the value of $f_{\mathrm{dI}}$, in case amplitude increases within that range of Section I. The EVA current and LCE acceleration waveforms obtained in this section correspond to the simulation results, obtained in seeking process for the fifth time interval, as in 


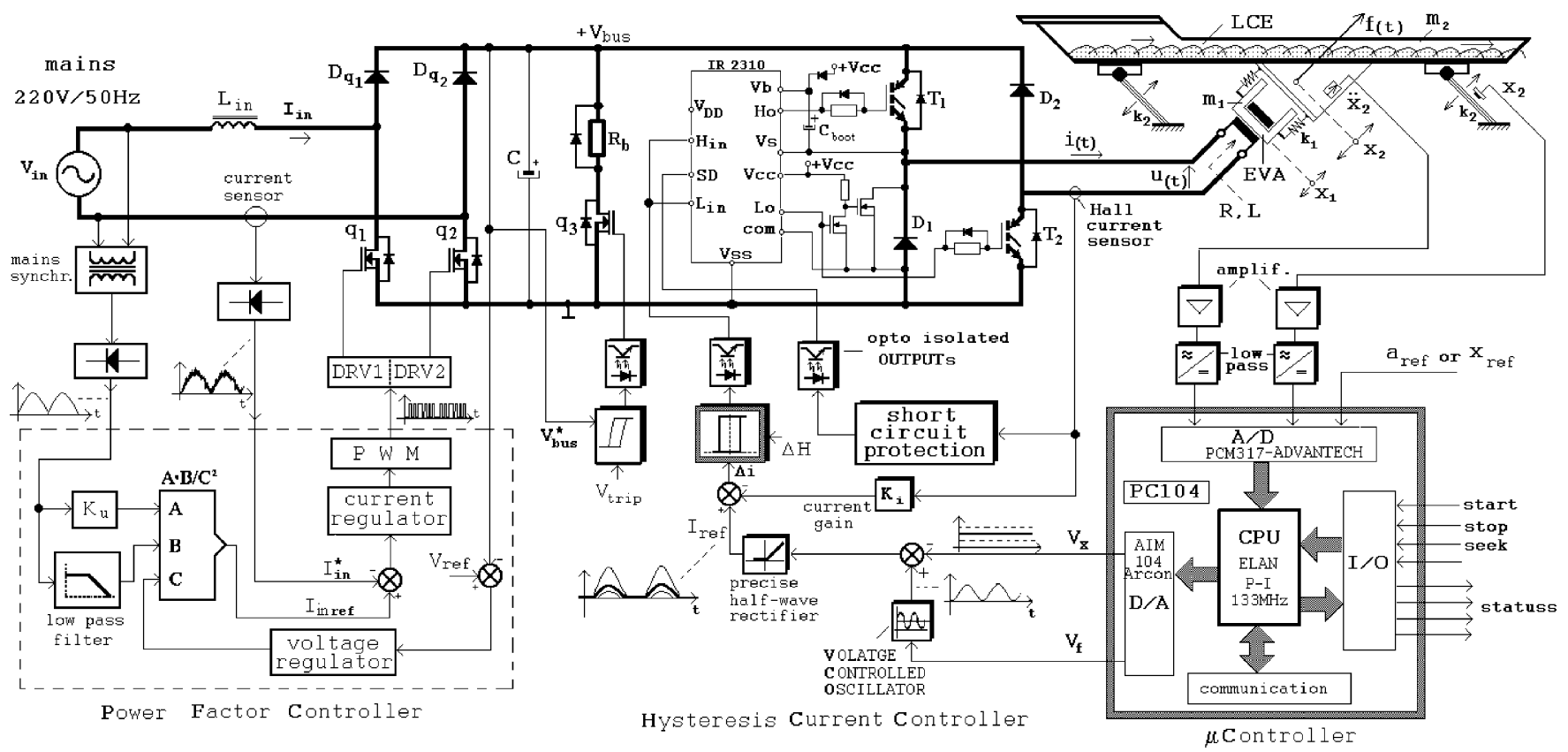

Fig. 20. Principal diagram of implemented ac/dc transistor converter for driving of EVA.

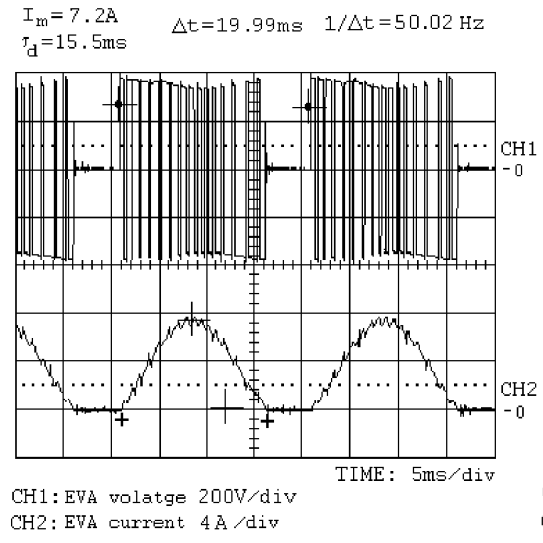

(a)

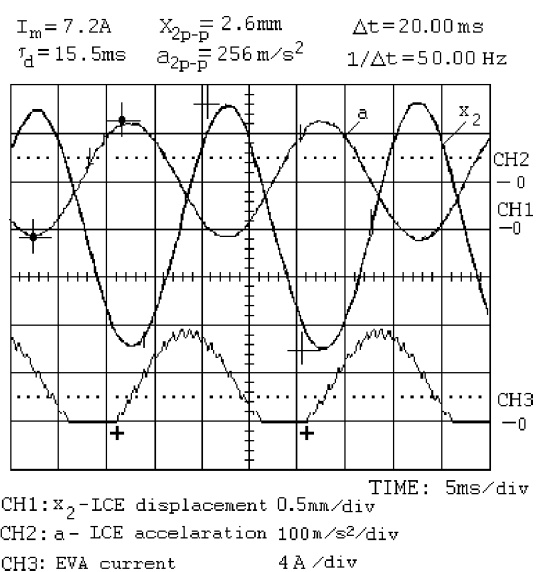

(b)

Fig. 21. Oscilloscopic records of characteristic waveforms for VCS with transistor control. (a) EVA current and EVA voltage. (b) LCE displacement, LCE acceleration, and EVA current.

Fig. 16(d). The acceleration amplitude of $a_{2 m}=31 / s^{2}$ approximately corresponds to the amplitude of LCE displacement, $X_{2 m}=0.18 \mathrm{~mm}$, for given driving frequency of $65 \mathrm{~Hz}$, i.e., $a_{2 m}^{*}=(2 \pi \cdot 65)^{2} \cdot 0.18 \cdot 10^{-3}=30.03 \mathrm{~m} / \mathrm{s}^{2}$.

Section II is shown in Fig. 23(b). When acceleration amplitude is equal to $a_{2 m}=42 \mathrm{~m} / \mathrm{s}^{2}\left(a_{2 p-p}=84 \mathrm{~m} / \mathrm{s}^{2}\right)$, the acceleration waveform takes almost sine form. In the observed section, the EVA current frequency is $f_{\mathrm{dII}}=60 \mathrm{~Hz}$. The EVA current and LCE acceleration waveforms obtained in this section correspond to the simulation results, which are obtained in seeking process for the fourth time interval, as in Fig. 16(c). The acceleration amplitude of $a_{2 m}=42 \mathrm{~m} / \mathrm{s}^{2}$ approximately corresponds to the amplitude of LCE displacement, $X_{2 m}=0.3 \mathrm{~mm}$, for a given driving frequency of $60 \mathrm{~Hz}$, i.e., $a_{2 m}^{*}=(2 \pi \cdot 60)^{2} \cdot 0.3$. $10^{-3}=42.63 \mathrm{~m} / \mathrm{s}^{2}$.

In the case of frequency decrease below $60 \mathrm{~Hz}$ (Section III), as shown on Fig. 23(c), a decrease of acceleration amplitude is caused. The EVA current and LCE acceleration waveforms obtained in this section correspond to the simulation results, obtained in seeking process for the third time interval as in Fig. 16(b). The acceleration amplitude of $a_{2 m}=24 \mathrm{~m} / \mathrm{s}^{2}\left(a_{2 p-p}=48 \mathrm{~m} / \mathrm{s}^{2}\right)$ approximately corresponds to the amplitude of LCE displacement, $X_{2 m}=0.2 \mathrm{~mm}$, for given driving frequency of $55 \mathrm{~Hz}$, i.e., $a_{2 m}^{*}=(2 \pi \cdot 55)^{2} \cdot 0.2 \cdot 10^{-3}=23.86 \mathrm{~m} / \mathrm{s}^{2}$.

Consequently, the frequency $f_{\mathrm{dII}}=60 \mathrm{~Hz}$ is in fact a real resonant frequency. The mathematical calculation for load mass and equivalent spring stiffness shows that resonant frequency $f_{\text {res }}$ is truly defined by the value of about $60 \mathrm{~Hz}$, i.e., $f_{\text {res }}=$ $(1 / 2 \pi) \cdot \sqrt{k_{2} / m_{2}}=0.159 \cdot \sqrt{10 \cdot 10^{6} / 67}=61.4 \mathrm{~Hz}$.

\section{CONCLUSION}

The mathematical model for the VCS with electromagnetic drive and power converter control circuits for its optimal control 


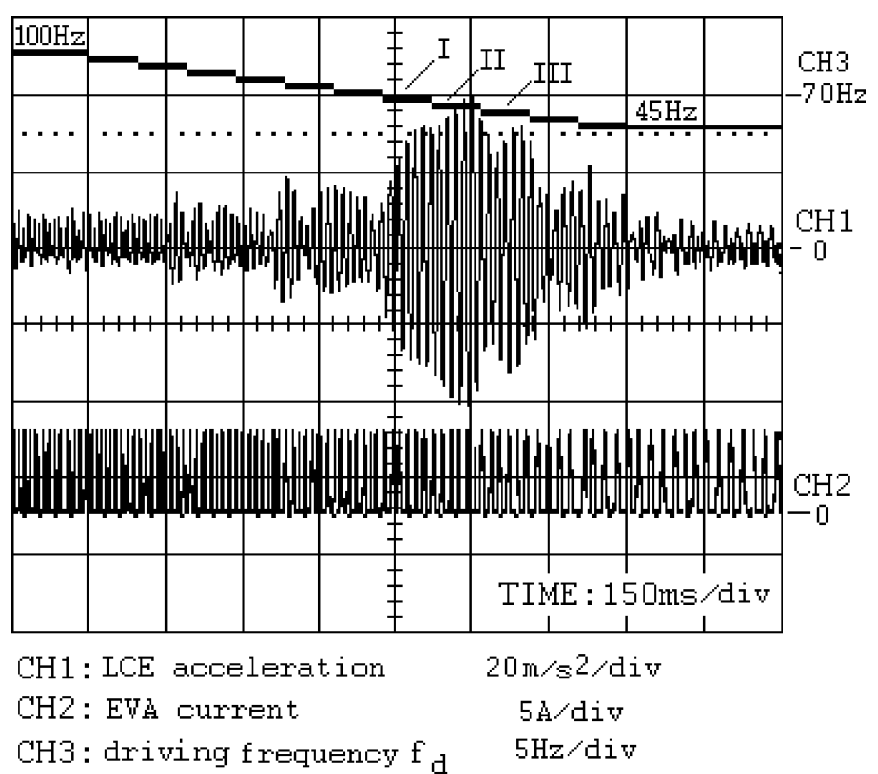

Fig. 22. Oscilloscopic records of resonant frequency seeking process.

is described in this paper. Simulation and experimental results refer to the case of SCR and switching drive.

It can be concluded, in scope of simulation and experimental results, that in the case of SCR converter, with phase control, the LCE displacement has "smooth" sine characteristic, although the EVA current is pulsating. Furthermore, change of firing angle provides amplitudes adjustment of the mechanical oscillations, but not their frequency, since the conventional SCR controller operates at a fixed frequency, which is imposed by the ac source. This converter injects undesirable harmonics and dc current component into mains supply. A serious problem can occur due to change of conveying material mass. Consequently, the mechanical resonant frequency also changes and the vibratory system will not be effective. The transistor switching converter with tolerance band current control can resolve these disadvantages. In this way, the EVA current is nondependent on mains frequency. The EVA current waveform is very similar to the case with phase control. The only difference is in current high-frequency ripple due to the hysteresis control. Drive current ripple does not effect the LCE oscillation waveform, since sine wave of displacement is "smooth," like that of the SCR drive. The vibratory conveying drive can operate in the mechanical resonance region. Resonance can be variable, depending on the conveying material mass change. It is necessary to find the resonant frequency for optimal and efficient operation. In the located resonant frequency region, it is possible to tune amplitude and duration of the EVA current, i.e., amplitude oscillation of the LCE.

In the above section, measured experimental results have been presented. These results were recorded on both a real SCR and transistor power converter prototypes for driving EVA. Simulation and experimental results prove that created simulation models describe successfully and satisfactorily observed electromagnetic vibratory conveying drive.

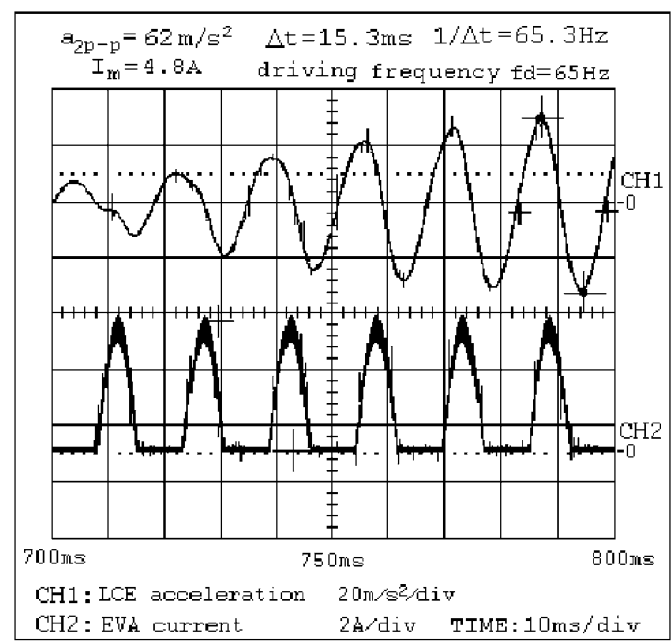

(a)
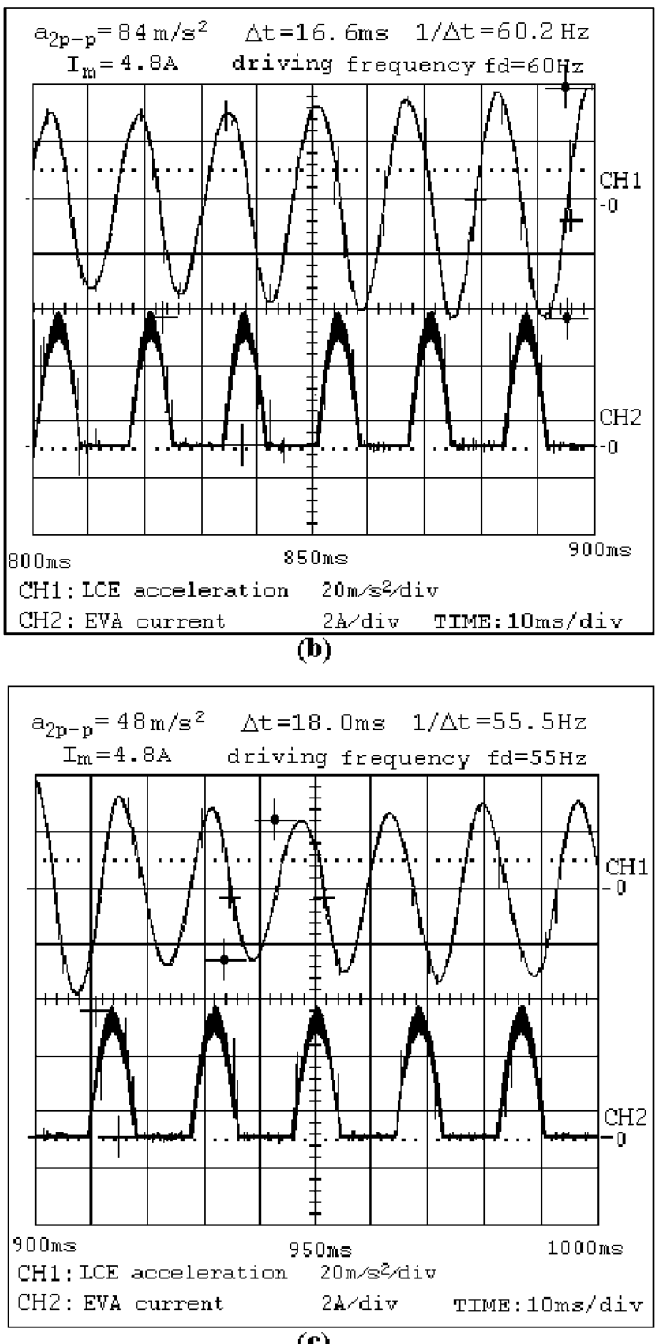

(c)

Fig. 23. Detailed resonant seeking process presentation. (a) Section I. (b) Section II. (c) Section III.

\section{ACKNOWLEDGMENT}

The authors are grateful for all constructive comments and valuable suggestions of the anonymous reviewers. 


\section{REFERENCES}

[1] I. F. Goncharevich, K. V. Frolov, and E. I. Rivin, Theory of Vibratory Technology. New York: Hemisphere Pub. Corp., 1990.

[2] E. M. Sloot and N. P. Kruyt, "Theoretical and experimental study of the transport of granular materials by inclined vibratory conveyors," Powder Technol., vol. 87, no. 3, pp. 203-210, 1996.

[3] H. El-Hor and S. J. Linz, "Model for transport of granular matter on an annular vibratory conveyor," J. Statistical Mechanics: Theory and Experiment Feb. 2005 [Online]. Available: http://ej.iop.org/links/q38/ 6\{XxvsDqDwumySTMU4x8HRQ/jstat5\02\102005.pdf

[4] H. El-Hor, S. J. Linz, R. Grochowsky, P. Walcel, C. A. Kruelle, M. Rouijaa, A. Gotzendorfer, and I. Rehberg, Model for transport of granular matter on vibratory conveyors [Online]. Available: www.uni-bayreuth.de/departments/ep5/preprints/elhor-p\&g-1191.pdf

[5] G. R. Soto-Yarritu and A. A. Martinez, "Computer simulation of granular material: Vibrating feeders," Powder Handling and Process., vol. 13, no. 2, Apr./Jun. 2001.

[6] T. Dyr and P. Wodzinski, "Model particle velocity on a vibrating surface," Physicochem. Problems Mineral Process. vol. 36, pp. 147-157, May 2002 [Online]. Available: http://www.iit.upco.es/docs/ 01GRS01.pdf

[7] M. A. Parameswaran and S. Ganapahy, "Vibratory conveying-analysis and design: A review," Mechanism Mach. Theory, vol. 14, no. 2, pp. 89-97, Apr. 1979.

[8] E. H. Werninck, Electric Motor Handbook. New York: McGraw-Hill, 1978.

[9] M. Joshi, "Performance Monitoring System for Electromagnetic Vibrating Feeders of Coal Handling Plant", Technical Paper Plant Maintenance Resource Center, Jul. 2002 [Online]. Available: www.plant-maintenance.com/articles/Feeder_Performance_Monitoring.pdf, M-News 27

[10] D. McGlinchey, "Vibratory conveying under extreme conditions: An experimental study," Advanced Dry Process. 2002, Powder/Bulk Solids, pp. 63-67, Nov. 2001.

[11] P. U. Frei, "An intelligent vibratory conveyor for the individual object transportation in two dimensions," in Proc. Int. Conf. Intelligent Robots and Systems (IEEE/RSJ 2002), Lausanne, Switzerland, Oct. 2002, pp. 1832-1837, EPFL.

[12] — Theory, Design and Implementation of a Novel Vibratory Conveyor Swiss Federal Institute of Technology, ETH, Zurich, Switzerland, 2002 [Online]. Available: http://e-collection.ethbib.ethz.ch/ecolpool/diss/fulltext/eth14426.pdf

[13] N. Jaksic and G. Maul, "Flexible air-jet tooling for vibratory bowl feeder systems," Int. J. Flexible Manufacturing Syst., vol. 14, no. 3, pp. 227-248, Jul. 2002.

[14] T. Doi, K. Yoshida, Y. Tamai, K. Kono, K. Naito, and T. Ono, "Feedback control for vibratory feeder of electromagnetic type," in Proc. ICAM'98, 1998, pp. 849-854.
[15] _ _ "Modeling and feedback control for vibratory feeder of electromagnetic type," J. Robotics Mechatronics, vol. 11, no. 5, pp. 563-572, Jun. 1999.

[16] — "Feedback control for electromagnetic vibration feeder," JSME Int. J., ser. C, vol. 44, no. 1, pp. 44-52, 2001.

[17] L. Han and S. K. Tso, "Mechatronic design of a flexible vibratory feeding system," Proc. I MECH-E- Part B, J. Eng. Manufacture, vol. 217, no. 6, pp. 837-842, Jun. 2003.

[18] S. Seely, Electromechanical Energy Conversion. New York: McGraw-Hill, 1962.

[19] R. Martinez and P. N. Enjeti, "A high performance single phase rectifier with input power factor correction," IEEE Trans. Power Electron., vol. 11, no. 2, pp. 311-317, Mar. 1996.

[20] A. F. de Souza and I. Barbi, "A new ZVS-PWM unity power factor rectifier with reduced conduction losses," IEEE Trans. Power Electron., vol. 10, no. 6, pp. 746-752, Nov. 1996.

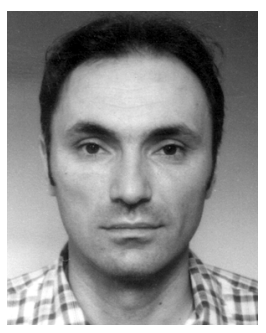

Željko V. Despotović (M'04) was born in Prijepolje, Serbia and Montenegro, in 1964. He received the B.Sc. and M.Sc. degrees in electrical engineering from the University of Belgrade, Serbia and Montenegro, 1990 and 2003, respectively. He is currently working toward the Ph.D. degree at the Power Converter Laboratory, Faculty of Electrical Engineering, University of Belgrade.

He has been with the Department of Mechatronics, Mihajlo Pupin Institute, Belgrade, since 1991. His research interests include the fields of power electronics, mechatronics, vibration control, and vibratory conveying systems.

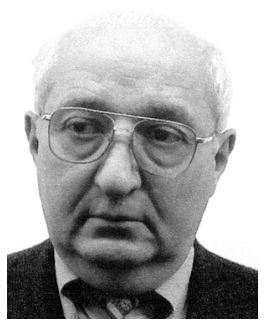

Zoran Stojiljković was born in Kruševac, Serbia. He received the B.Sc., M.Sc., and Ph.D. degrees in electrical engineering from the University of Belgrade, Serbia and Montenegro, in 1962, 1971, and 1977, respectively.

From 1963 through 1978, he was with the Mihajlo Pupin Institute, Belgrade, where he worked on research projects in automatic control, robotics, and biomedical engineering. From 1978 to 1987, he was with the Center for Multidisciplinary Studies, University of Belgrade, where was engaged in research and teaching in the areas of biomedical engineering and pattern recognition. Since 1987, he has been the Professor of Power Converters and Power Converters Control in the Faculty of Electrical Engineering, University of Belgrade. His research interests include the areas of power electronics, ac drive, mechatronicsm and biomedical engineering. 